\title{
Research on Bearing Capacity of Simply Supported Skew Bridge Based on Load Test
}

\author{
Songhui $\mathrm{Li}^{1, *}$,Honglei $\mathrm{Li}^{1}$, and Jinjin $\mathrm{Gao}^{1}$ \\ ${ }^{1}$ School of Civil Engineering and Architecture, Shandong University of Science and Technology, Qingdao,Shandong,China.
}

\begin{abstract}
The purpose of this paper is to use static and dynamic load tests to evaluate the mechanical performance of a simply supported skew slab bridge and to evaluate its actual bearing capacity. Firstly, the Midas Civil software is used for theoretical simulation, and secondly, the deflection, strain, and dynamic response of the key section of the bridge are studied through static and dynamic load tests. Finally, the measured values and theoretical values are compared and analyzed. The results show that: under static load, the relative residual deflection and relative residual strain of the measuring point of the structure are between $-13.8 \% \sim-0.4 \%$ and $-16.7 \% \sim 1.8 \%$ respectively; Under dynamic load, the first-order vertical natural frequency of the test section is 7.813 , and the damping ratio is 0.0316 , indicating that the bridge is in an elastic working state under the test load, and the stiffness and bearing capacity can meet the requirements of the current code.
\end{abstract}

\section{Introduction}

In recent years, in order to meet the development and demand for road transportation, a large number of bridges of different structures have been built. However, for newly built bridges and old bridges, due to environmental effects, vehicle loads and other unfavorable factors, different degrees of damage will occur, which will reduce the bearing capacity of the bridge. Therefore, it is very important to evaluate the bearing capacity of the bridge through bridge inspection. The bridge field load test is the most common way to determine the performance of the bridge. Certain test loads are applied to the bridge structure and components, and the stress, strain and displacement data of the bridge structure are tested and analyzed, so as to evaluate the actual stress state and safe operation of the bridge.

Tang Like ${ }^{[1]}$ evaluated the safety performance of the Yuele high-pier long-span rigid frame bridge through a combination of load test and theoretical calculation. Dong Feng ${ }^{[2]}$ took Jiangshan Bridge as an example, conducted static and dynamic load tests, and systematically studied the overall performance of the bridge. At present, there are few load test studies on simply supported skew bridges at home and abroad ${ }^{[3-6]}$. Compared with straight bridges, skew bridges have more complicated mechanical characteristics, but they are widely used in bridge construction because they can shorten the bridge span and save cost. Therefore, the load test on the continuous simply supported skew bridge has great engineering application value.

This paper takes a three-span simply supported skew bridge as the engineering background. Through on-site static load and dynamic load tests on the bridge, the performance parameters of the simply supported skew bridge after being stressed are tested, the operation capacity is analyzed, and the actual bearing capacity of the bridge structure is comprehensively evaluated. The research results can provide a reference for the preparation of such bridge test methods and related specifications.

\section{Bridge Overview}

The bridge is a double-span bridge with a total length of $46.2 \mathrm{~m}$. The highway design load is car-super 20, and the full width is $28 \mathrm{~m}$. The lateral layout of the bridge deck is $0.5 \mathrm{~m}$ (anti-collision wall) $+12 \mathrm{~m}$ (left carriageway) $+1 \mathrm{~m}$ (guardrail) $+1 \mathrm{~m}$ (isolation belt) $+1 \mathrm{~m}$ (guardrail) $+12 \mathrm{~m}$ (right carriageway) $+0.5 \mathrm{~m}$ (guardrail), full oblique angle $70^{\circ}$. The superstructure type is $3 \times 13 \mathrm{~m}$ pre-stressed concrete simply supported hollow slab beams; 13 beams are arranged horizontally on the left and right widths; the piers are multi-column, stone-masonry gravity abutments. The schematic diagram of the bridge layout is shown in Figure 1.

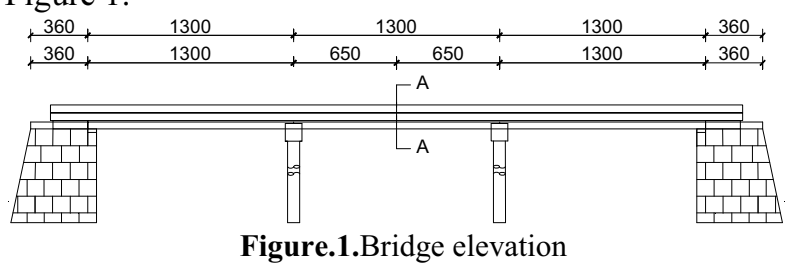

In recent years, with the advancement of science and technology and the maturity of finite element theory, various finite element software and special bridge calculation software have been developed rapidly, and

$\overline{\text { "Li Songhui@songhui.1@163.com.org }}$ 
have been widely used in bridge analysis, design and construction $^{[7]}$. According to the characteristics of the bridge structure, this paper uses the finite element software Midas Civil to establish a bridge structure calculation model as shown in Figure 2.

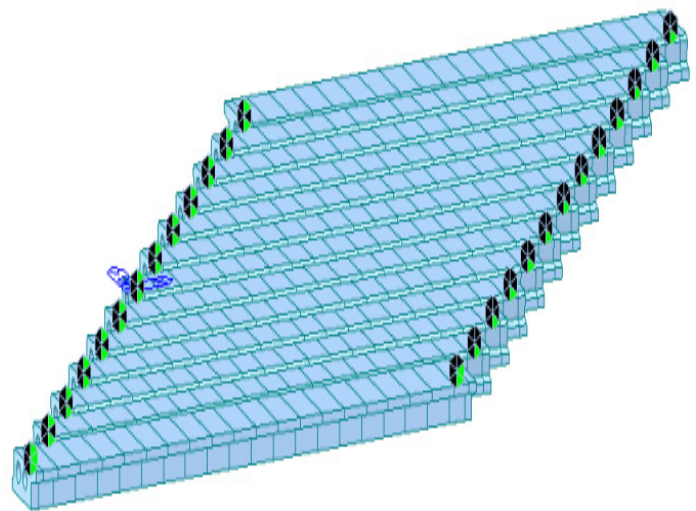

Figure.2.Structural finite element model (spatial grid model)

\section{Bridge static load test}

\subsection{Bridge static load test conditions}

The static load test of the bridge is based on the design test plan of the bridge, adopting the principle of internal force and deformation equivalent, selecting the test section at the most unfavorable position of the structure, and determining the size and location of the test load according to the control internal force of the bridge, and applying static force to it $\operatorname{Load}^{[8]}$.

The test bridge is a $(3 \times 13) \mathrm{m}$ prefabricated simplesupported hollow slab girder. The R-2\# span is selected for static load test. The main test conditions are shown in Table 1.

\begin{tabular}{|c|c|c|c|}
\hline Test conditions & $\begin{array}{l}\text { Control } \\
\text { section }\end{array}$ & Test items & Test content \\
\hline \multirow[b]{2}{*}{$\begin{array}{l}\text { Working } \\
\text { condition } 1\end{array}$} & \multirow[b]{2}{*}{$\begin{array}{c}\text { A-A } \\
\text { section }\end{array}$} & \multirow{2}{*}{$\begin{array}{c}\text { Maximum } \\
\text { positive } \\
\text { bending } \\
\text { moment } \\
\text { under } \\
\text { eccentric } \\
\text { load }\end{array}$} & $\begin{array}{l}\text { Strain of each } \\
\text { control } \\
\text { measuring } \\
\text { point under } \\
\text { various loads }\end{array}$ \\
\hline & & & $\begin{array}{l}\text { Deflection of } \\
\text { each control } \\
\text { measuring } \\
\text { point under } \\
\text { various loads }\end{array}$ \\
\hline $\begin{array}{l}\text { Working } \\
\text { condition } 2\end{array}$ & $\begin{array}{c}\text { A-A } \\
\text { section }\end{array}$ & $\begin{array}{l}\text { Maximum } \\
\text { positive } \\
\text { bending } \\
\text { moment } \\
\text { under } \\
\text { medium } \\
\text { load }\end{array}$ & $\begin{array}{l}\text { Strain of each } \\
\text { control } \\
\text { measuring } \\
\text { point under } \\
\text { full load } \\
\text { Deflection of } \\
\text { each control } \\
\text { measuring } \\
\text { point under } \\
\text { full load }\end{array}$ \\
\hline
\end{tabular}

\subsection{Test efficiency}

According to the highway bridge load test regulations, the value of the static test load efficiency coefficient $\eta_{q}$ is related to the calculated value under the test load and the controlled load. The calculation formula of $\eta_{q}$ is

$$
\eta_{q}=\frac{s_{s}}{s(1+\mu)}
$$

According to the above calculation, the static load efficiency coefficient of the test item is shown in Table 2. It can be seen from the table that the load efficiency coefficient is 1.02 and 1.01, which meets the requirements of the specification ${ }^{[9]}$.

Table 2.Static load efficiency factor

\begin{tabular}{|c|c|c|c|c|}
\hline \multicolumn{1}{c|}{ Table 2.Static load efficiency factor } \\
$\begin{array}{c}\text { Test } \\
\text { conditions }\end{array}$ & Test items & $\begin{array}{c}\text { Design } \\
\text { value } \\
{[\mathrm{s}(1+\mu)]}\end{array}$ & $\begin{array}{c}\text { Test } \\
\text { value } \\
(\mathrm{S}) \\
(\mathrm{KN} \cdot \mathrm{m})\end{array}$ & $\begin{array}{c}\text { Test } \\
\text { efficiency } \\
(\eta) \%\end{array}$ \\
\hline $\begin{array}{c}\text { Working } \\
\text { condition } \\
\text { one }\end{array}$ & $\begin{array}{c}\text { Eccentric } \\
\text { load A-A } \\
\text { maximum } \\
\text { positive } \\
\text { bending } \\
\text { moment }\end{array}$ & 251.35 & 255.71 & 1.02 \\
\hline \multirow{2}{*}{$\begin{array}{c}\text { Normal } \\
\text { load A-A } \\
\text { cross } \\
\text { condition } \\
\text { two }\end{array}$} & $\begin{array}{c}\text { section the } \\
\text { most } \\
\text { Large } \\
\text { positive } \\
\text { bending } \\
\text { moment }\end{array}$ & 183.30 & 185.76 & 1.01 \\
& & & & \\
\hline
\end{tabular}

\subsection{Deflection test}

The actual measured value and theoretical calculation of the deflection of each deflection measuring point under static load test condition 1 and condition 2, the deflection calibration coefficient and the relative residual deformation are shown in Figure 3-5.

It can be seen from Figure 3 that the measured deflection values under the two load conditions are both smaller than the calculated values, and the measured and theoretically calculated values are consistent along the plate length. From Fig 4 and Fig 5, the calibration coefficient of each deflection measuring point of working condition 1 is between $3.4 \sim 0.60$, and the relative residual deformation is $-10.4 \% \sim-3.4 \%$; the checking coefficient of each deflection measuring point of working condition 2 is between $0.32 \sim$ Between 0.68, the relative residual deformation is $-13.8 \%$ to $-0.4 \%$. 


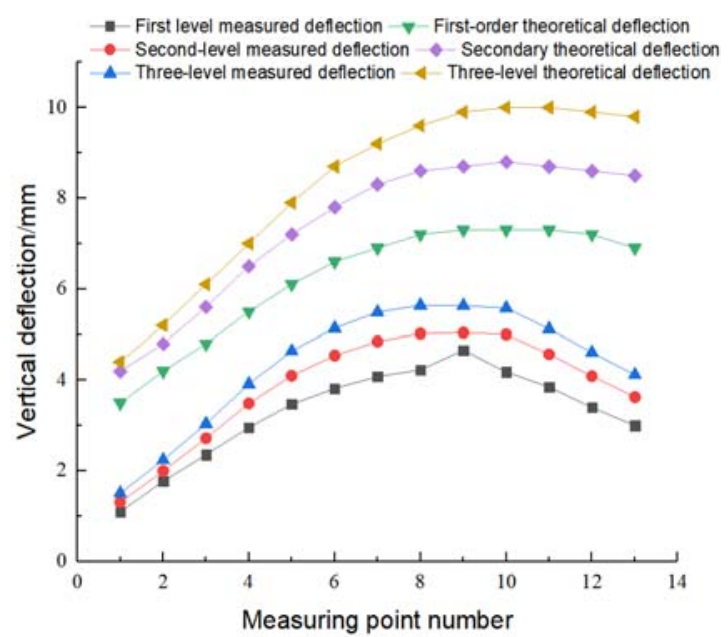

(a) Working condition one

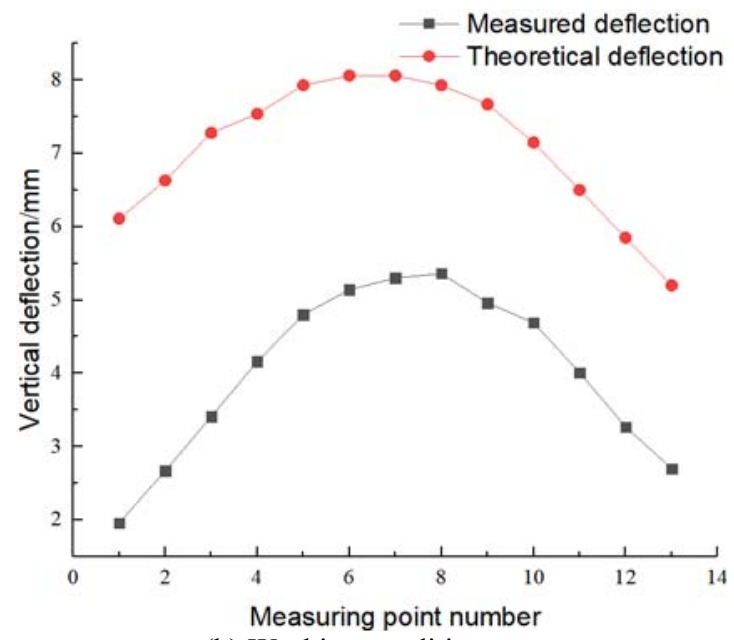

(b) Working condition two

Figure.3.Comparison of deflection under different working Conditions

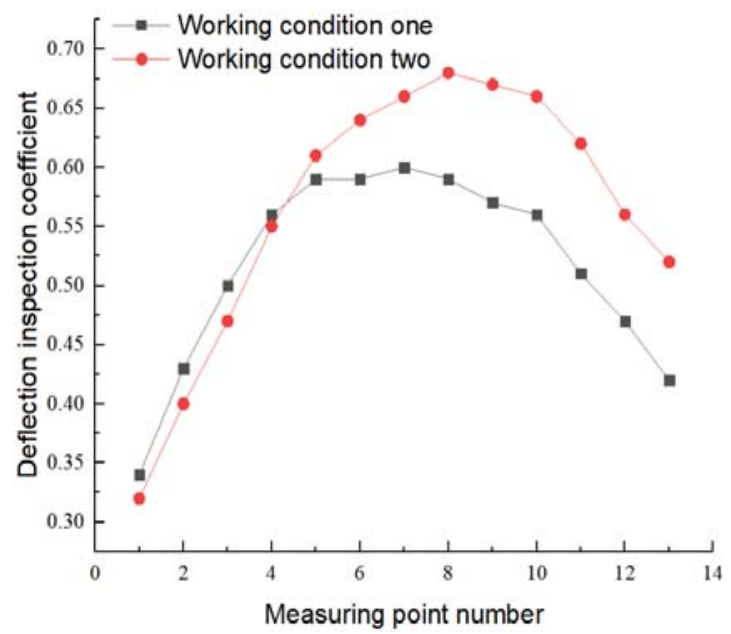

Figure.4.Deflection calibration coefficient under different working conditions

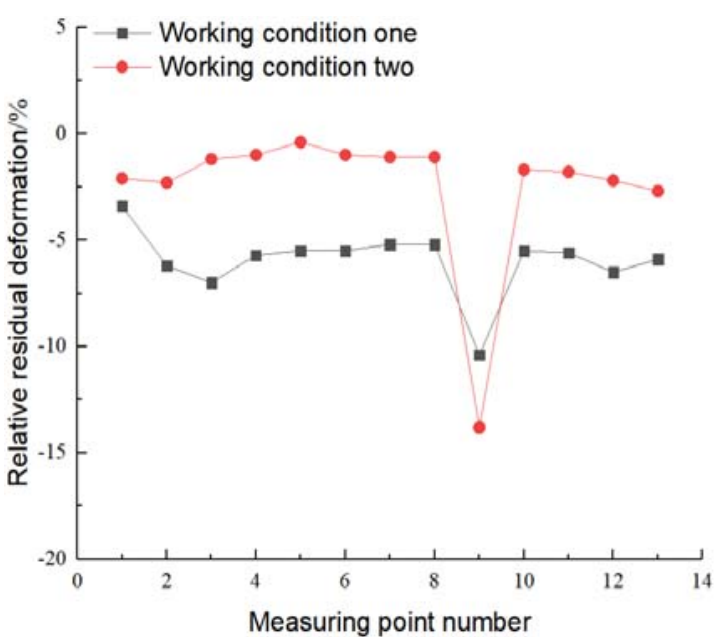

Figure.5.Comparison of relative residual deformation under different working conditions

\subsection{Strain test}

The measured strain values, theoretical calculated values, strain calibration coefficients and relative residual strains of the control section under static load test condition 1 and condition 2 are shown in Figure 6-8.

It can be seen from Fig 6 that the measured strain values under the two load conditions are both smaller than the calculated values, and the measured values and theoretical calculated values are consistent along the plate length. It can be seen from Fig 7 and Fig 8 that the calibration coefficient of each strain measurement point of working condition 1 is between 0.48 and 0.59 , and the relative residual strain is $-16.9 \%$ to $-2.1 \%$; The coefficient is between 0.45 and 0.54 , and the relative residual strain is $-7.9 \%$ to $1.8 \%$.

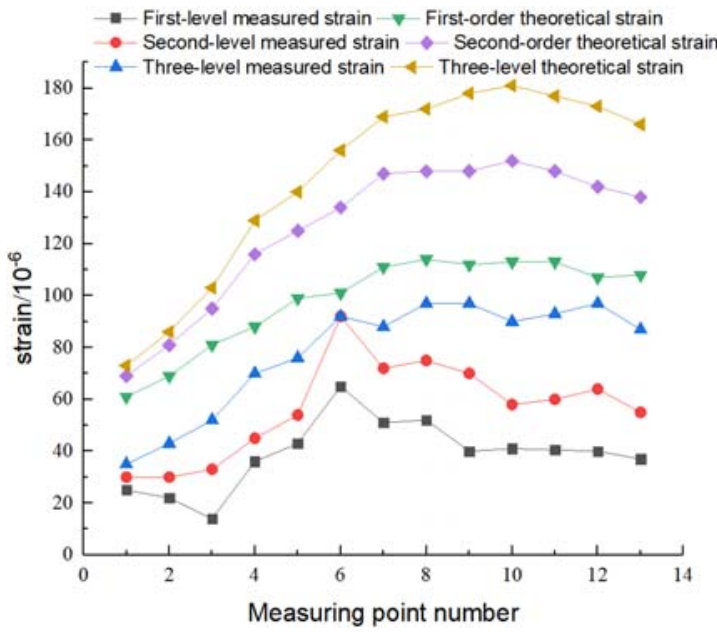

(a) Working condition one 


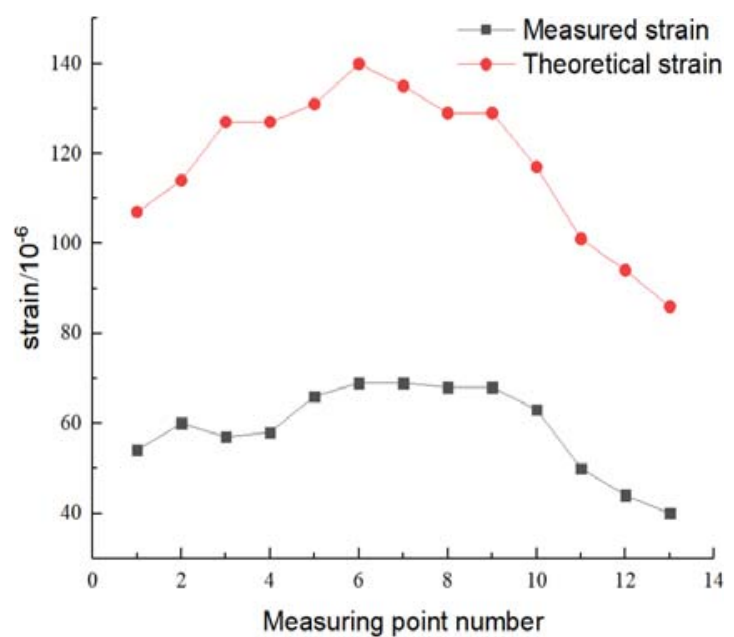

(b) Working condition one

Figure.6.Strain comparison under different working conditions

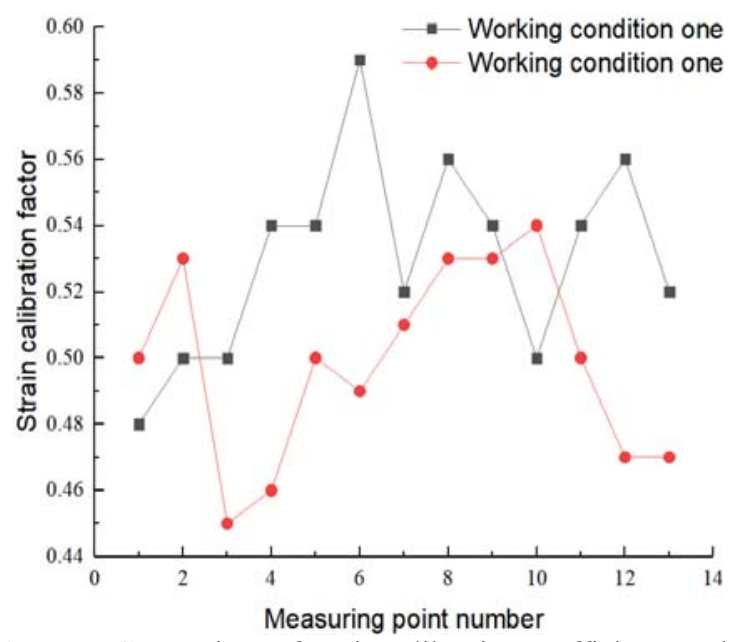

Figure.7. Comparison of strain calibration coefficients under different working conditions

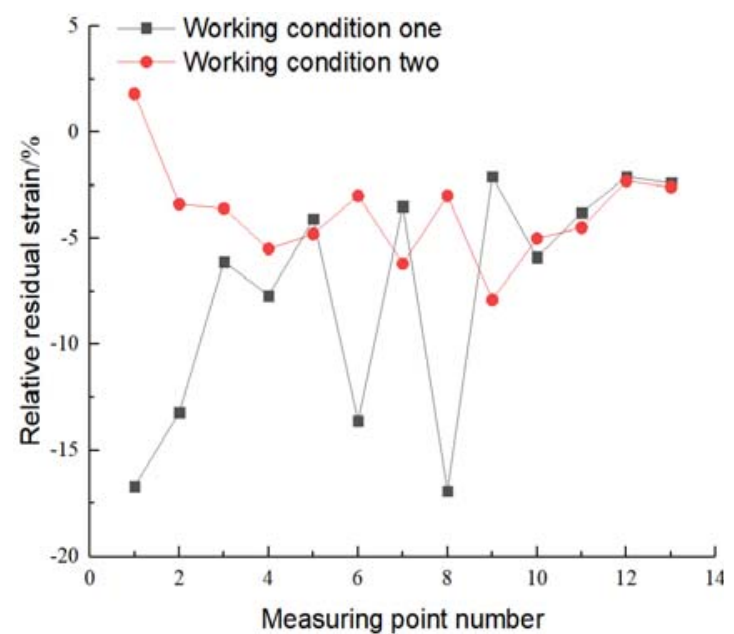

Figure.8.Comparison of relative residual strains under different working conditions

\section{Bridge dynamic load test}

The bridge dynamic load test mainly adopts a certain excitation method to make the bridge structure vibrate correspondingly, determine its natural vibration characteristics, impact coefficient, dynamic response and other parameters, compare the test results with theoretical values, and evaluate the dynamic characteristics of the structure.

The space three-dimensional finite element model is established by Midas Civil software, and the first-order mode diagram of the bridge is shown in Figure 9. After data analysis and calculation, the basic frequency test value and theoretical calculation value of structure natural vibration are obtained. The results are shown in Table 3.

Table 3.Basic frequency of structural natural vibration

\begin{tabular}{|c|c|c|c|}
\hline \multirow{2}{*}{$\begin{array}{c}\text { Measured } \\
\text { frequency } \\
\text { order }\end{array}$} & \multicolumn{2}{|c|}{ Frequency/Hz } & \multirow{2}{*}{$\begin{array}{c}\text { Damping } \\
\text { ratio }\end{array}$} \\
\cline { 2 - 3 } & test value & $\begin{array}{c}\text { Theoretical } \\
\text { value }\end{array}$ & 0.0316 \\
\hline First order & 5.18 & 7.813 & 0.0 \\
\hline
\end{tabular}

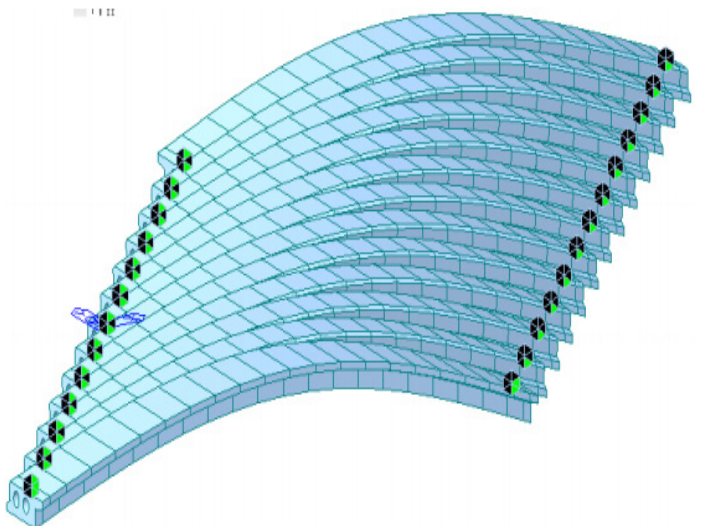

Figure.9.First-order mode of bridge

\section{Conclusion}

In this paper, through the finite element calculation and load test of a simply supported skew bridge, the following conclusions are obtained:

(1) The test deflection check coefficient of each working condition of the bridge static load is $0.32 \sim 0.68$, and the strain check coefficient is $0.45 \sim 0.59$, which are all less than 1.0, indicating that the strength and stiffness of the test control section meet the design load requirements.

(2) After unloading in each working condition, the relative residual deflection value of the section deflection measurement point is $-13.8 \% \sim-0.4 \%$, and the relative residual strain value is $-16.7 \% \sim 1.8 \%$, which does not exceed the upper limit of the specification by $20 \%$, indicating that the bridge It is in the elastic working stage under the design load.

(3) The test value of the first-order vertical natural frequency of the superstructure of the bridge span is 7.813 , the damping ratio is 0.0316 , and the measured frequency is greater than the theoretical value, indicating that the actual stiffness of the bridge is better and meets the design requirements. 


\section{References}

1. Tang Like, Jia Yi, Ji Yuntao, et al. Load test of high pier and long span continuous rigid frame bridge. Railway Construction.57,7 (2017)

2. Dong Feng,Zhang Jiandong,Li Xuehong, et al.Static and dynamic load test research of steel truss web prestressed concrete composite beam bridge. China and Foreign Highway,35,2(2015)

3. Qi Xingjun, Zhao Yue, Zhao Qi.Numerical method for static load test of skew bridge based on modal deflection. Chinese Journal of Building Science and Engineering,37,3(2020)

4. Luo Hao, Guo Xiangrong.Analysis of vehicle-bridge coupling vibration of multi-span oblique simply supported T-beam bridge.China Railway Science,30,4(2009)

5. Xi Guangheng, Chen Xiao, Liu Bin.Field load test study on externally prestressed bridges. China and Foreign Highway,28,4(2008)

6. Wang Wei, Zhang Yuping, Feng Longcheng. et al.Research on optimization of static load test of multi-span cable-stayed bridge with low towers, World Bridges,45,1(2017)

7. Ge Junying.Guide for the use of bridge engineering software MIDAS CIVIL. Beijing: People's Communications Press,(2013)

8. Institute of Highway Research, Ministry of Transport. JTG /TJ21-2011 Test and Evaluation Regulations for the Bearing Capacity of Highway Bridges. Beijing: People's Communications Press, (2011)

9. Changan University.JTG/TJ21-01-2015 Highway Bridge Load Test Regulations. Beijing: People's Communications Press,(2015) 